Revista aSEPHallus de Orientação Lacaniana

Núcleo Sephora de Pesquisa sobre o Moderno e o Contemporâneo

ISSN 1809 - $709 \mathrm{X}$

\title{
O Outro lacaniano, uma razão no real $^{1}$
}

\section{Dany-Robert Dufour}

Filósofo

Professor aposentado da Universidade Paris VIII Autor de $A$ Cidade perversa (Ed. Civilização Brasileira), O divino Mercado (Ed. Companhia de Freud), Os mistérios da trindade (Ed. Companhia de Freud), A arte de reduzir as cabeças (Ed. Companhia de Freud), Le délire occidental (Éditions Les Liens qui libèrent) e $A$ existência de Deus comprovada por um filósofo ateu

(Ed. Civilização Brasileira)

E-mail: dany.dufour@free.fr

Resumo: Não esperamos nossa época para percebermos a prematuração do homem. Existe todo um campo de estudos presente desde os primórdios da filosofia ocidental. Desde o século XX, os antropólogos e os biólogos falam da neotenia do homem. Se os períodos precedentes definiam espaços marcados pela distância entre o sujeito e aquele que o funda, a pós-modernidade é um espaço definido pela abolição da distância entre o sujeito e o Outro. Quando o Outro falta podemos erigir com toda força um tipo de Outro que assegure absolutamente o sujeito contra todo risco de ausência.

Palavras-chave: psicanálise; neotenia; Outro; real; pós-modernidade.

\section{L'Autre lacanien, une raison dans le réel}

On n'a pas attendu notre époque pour s'apercevoir la prématuration de l'homme. Il existe tout un champ d'études présent depuis les débuts de la philosophie occidentale. Depuis le XX' siècle, les anthropologues et les biologistes parlent de la néoténie de l'homme. Si les périodes précédentes définissaient des espaces marqués par la distance du sujet à ce qui le fonde, la post-modernité est un espace défini par l'abolition de la distance entre le sujet et l'Autre. Lorsque l'Autre manque, on peut ériger à toute force une sorte d'Autre qui garantisse absolument le sujet contre tout risque d'absence.

Mots-clés: psychanalyse; néoténie; Autre; réel; post-modernité.

\section{The lacanian Other, a reason in the real}

We do not wait for our time to realize the prematuration of man. There is a whole field of study present since the beginnings of western philosophy. Since the twentieth century, anthropologists and biologists have been talking about man's neoteny. If the preceding periods defined spaces marked by the distance between the subject and the one that founds him, postmodernity is a space defined by the abolition of the distance between the subject and the Other. When another is lacking, we can erect with all force a type of Other that absolutely assures the subject against all risk of absence.

Keywords: psychoanalysis; neoteny; Other; real; postmodernity. 


\section{O Outro lacaniano, uma razão no real}

\section{Dany-Robert Dufour}

Agradeço vivamente aos organizadores deste VI Simpósio do ISEPOL por terem me convidado, especialmente a Tania Coelho dos Santos e a Flávia Lana Garcia de Oliveira, que conheci em Paris. É necessário, no entanto, que vocês saibam que eu tenho um grande defeito: não sou psicanalista, mas filósofo. Em minha defesa, eu diria que sou um filósofo um pouco bizarro, já que frequento há longo tempo a psicanálise, não somente seus autores mais notórios, como Freud e Lacan, mas também seus praticantes, qualquer que seja a escola a que eles pertençam. Foi assim que uma bela amizade me ligou ao saudoso Serge Leclaire, a quem eu devo muito. Mas não estou aqui para Ihes contar minha vida.

Se estou aqui, é porque um livro que publiquei na França há alguns anos acaba de ser traduzido pela editora Civilização Brasileira. Assim, ocorre que eu faço, neste livro, referência a uma noção que Freud e Lacan utilizaram muito, a noção de prematuração. Ela se refere ao fato de que o homem é o único dos mamíferos superiores que é notoriamente inacabado no nascimento. Em suma, ele vem ao mundo cedo demais: mal terminado, "remendado" diriam alguns, isto é, "nem feito, nem a fazer", como se diz pejorativamente em francês. Ou mesmo "safado", como denunciava com força e desespero Antonin Artaud.

Vejam aqui algumas provas ou indícios de certa prematuração específica do homem no nascimento: paredes cardíacas não fechadas, imaturidade pós-natal do sistema nervoso piramidal, insuficiência dos alvéolos pulmonares, caixa craniana não fechada (cf. a moleira), circunvoluções cerebrais mal desenvolvidas, ausência de polegar opositor, ausência de sistema piloso, ausência de dentição de leite no nascimento - sem contar, nos homens, a ausência do osso peniano que, em certas circunstâncias, pode falhar cruelmente - não é queridos amigos? Em suma, o homem é um ser de nascimento prematuro, sujeito a uma maternagem, incapaz de alcançar seu desenvolvimento germinal completo e, entretanto, capaz de se reproduzir e de transmitir seus traços de juvenilidade, que são normalmente transitórios em outros animais.

Não esperamos nossa época para percebermos esta prematuração do homem. Tentei mostrar neste livro que acaba de ser traduzido ${ }^{2}$ que existe todo um campo de estudos, presente desde os primórdios da filosofia ocidental, que se inclinou para a questão do inacabamento originário do homem - eu penso, por exemplo no Protágoras de Platão. E isso continuou até o século XX, já que, desde então, os antropólogos e os biólogos falaram, para evocar esta prematuração, da neotenia do homem ${ }^{3}$, isto a partir de 1926 , depois do célebre artigo do anatomista holandês Louis Bolk.

Assim, é por ali que a aventura humana começa, com um ser que não adveio, incapaz de se virar sozinho - chamaria, portanto, o muito-baixo. Freud, por sua vez, avança aqui com o termo Hilflosigkeit, desamparo em espanhol e em português, que se relaciona à aflição originária do 
homem. Não se sabe o suficiente sobre quanto este conceito cintila no decorrer da longa elaboração freudiana (a primeira ocorrência aparece em 1895 e a última em 1937). Encontramos especialmente no texto intitulado Inibição, sintoma, angústia, publicado em 1926, mesmo ano do artigo inaugural de Bolk, esta notação abertamente neotônica: "Dentre os fatores que participam da causação das neuroses [...], [é preciso guardar] o estado de aflição e de dependência [Hilflosigkeit] longamente prolongada do filhote do homem". A existência intrauterina do homem aparece face à da maioria dos animais relativamente abreviada; o filhote de homem é lançado no mundo mais inacabado do que eles (Freud, 1926/1993).

Freud, portanto, concede um lugar bastante central à neotenia, uma vez que ela lhe permite uma construção completamente original do fato neurótico. À questão tratada neste texto, "De onde vem a neurose ", Freud responde, com efeito, localizando três fatores essenciais dentre os quais se encontra, em primeiro lugar, o fator biológico, o estado de aflição e dependência do filhote do homem, explicitamente ligado à sua prematuração: "Este fator biológico instaura, portanto, as primeiras situações de perigo e cria a necessidade de ser amado, que não abandonará mais o ser humano". A neotenia, avança em alguma medida Freud, cria a necessidade de amor, a qual engendra a neurose.

Onde Freud foi buscar este termo? Eu devo evitar aqui minhas inclinações culpáveis pelos estudos teológicos. Foi o que me levou um dia a descobrir que este termo Hilflosigkeit simplesmente vinha da teologia da língua alemã e, mais precisamente, de Lutero. Este emprega, de fato, muito o termo Hilfe, a "ajuda", neste caso, a ajuda de Deus, necessária para resgatar o homem, este hilf-los (isto é, privado de hilfe), este homem tão baixo. Tão baixo para Lutero que este chegou, em um famoso sermão, até a compará-lo a um "dejeto caído no mundo pelo ânus do diabo"4 - o que nos leva à exata oposição do homem como rei da criação (Lacan, 1959-1960/1986). A neotenia, a Hilflosigkeit, engendra então uma necessidade de amor, que pode chegar à necessidade de amor de Deus.

Assim, está aí uma ideia que Lacan retomará a partir da sua entrada na psicanálise, em "O estádio do espelho", de 1936, cujo texto original está, como vocês sabem, perdido, mas que se conhece mais ou menos pelo artigo de 1938 sobre "a família", publicado na Enciclopédia francesa, depois pela reescrita deste texto em 1949. Lacan faz aí explicitamente da neotenia do homem um pivô de sua demonstração (eu cito a frase-chave: "não é preciso hesitar em considerar o homem como um animal de nascimento prematuro").

A tese de Lacan sobre o estádio do espelho dá, com efeito, um lugar de privilégio à neotenia, já que é disso que ele parte: o inacabamento orgânico do homem, se ensina, é suplantado por uma experiência decisiva de natureza psíquica no processo de formação do indivíduo. Esta experiência, Lacan toma emprestado das teses neodarwinianas de Wallon (expostas em "As origens do caráter na criança", publicado em 1934). Elas fazem da captação especular e espetacular, onde a criança se reconhece e unifica seu eu no espaço, o momento de uma experiência que comanda o acesso a uma 
ordem de coordenação mais ampla. A particularidade desta experiência vem disso que se pode também compreender como o último ato de maturação natural que precipita decisivamente o sujeito no mundo humano. Se deve, em suma, compreender o estádio do espelho como o momento decisivo no qual a falta de corpo do neóteno o destina a desdobrar sua vida em uma irremediável ficção. 0 real - a falta de corpo - e o imaginário - ser condenado à ficção - são, em suma, ligados.

Poderíamos tomar esta referência de Lacan à neotenia como anedótica e reenviá-la à história antiga. Assim, perto de quarenta anos após o estádio do espelho, quando ele tinha o costume de situar sua entrada na psicanálise, Lacan, na última década de seu ensino, em 1974, persistiu e insistiu em dizer que a neotenia de Bolk era fundamental para sua elaboração. Em "A terceira", quer dizer, a terceira e última conferência feita em Roma, Lacan declara, de fato, em sua sintaxe tão particular:

A relação do homem, do que se chama por esse nome, com seu corpo, se há algo que destaca que ela é imaginária, é o alcance que a imagem aí adquire. De início, destaquei que para isso, era preciso haver uma razão no real. Só a prematuração o explica. Isto não é meu, é de Bolk - nunca busquei ser original, sempre busquei ser lógico. Essa preferência pela imagem vem do fato de que o homem antecipa sua maturação corporal, com tudo que isso comporta, a saber, que ele não pode ver um de seus semelhantes sem pensar que ele toma o seu lugar - então, naturalmente, ele o vomita. (Lacan, 2011, dez., p. 22-23).

Algumas linhas mais abaixo, Lacan acrescenta, em uma anotação lapidar, uma ideia capital, já que ela simplesmente permite fazer o laço entre a neotenia e o Outro, grande A: "O que há de mais espantoso é que isso [a prematuração, a antecipação da maturação pela imagem e a rivalidade] permitiu o deslize do mandamento de Deus". A observação, enigmática, é pouco desenvolvida, mas compreendemos disso que o Outro, e mesmo o Outro em apoteose, o próprio Deus, foi introduzido na relação humana pela via do real da neotenia!

Então, isso me permitiu conjecturar que o sujeito, este muito-inferior, em geral não encontra nada melhor a fazer, para tentar sair desta relação, do que se submeter ao que é preciso chamar de Muito-alto. Quero dizer que haverá remediação se eu, ser finito no tempo e no espaço, mas tão malacabado no real, eu vier a supor um ser infinito em relação ao qual eu me coloco em posição de tudo dever. Assim, eu posso supor este ser, já que eu falo e falar é também fabular. Portanto, nada me impede de inventar no discurso o que não existe no real, mas do qual tenho necessidade para viver. Porque, se eu o suponho, Ele, o Muito-Alto, a quem em chamo o grande sujeito - é aliás exatamente o que quer dizer a palavra "sujeito". Sujeito, Subjectum, isso quer dizer submisso, quer dizer ser "posto sob", quer dizer "colocado abaixo". É preciso que baste que eu conjecture um grande Sujeito suposto tudo saber, tudo poder e tudo ver para que eu encontre enfim meu lugar, como 
sujeito deste ser. Este que eu chamaria o grande Sujeito responde então a esta definição de Aristóteles: "Ele é aquele" - dizia ele na Metafísica - "em torno do qual todo o resto se ordena". Em outros temos, o homem é certamente um "animal político", como o dizia Aristóteles, mas é em acréscimo um estranho animal, já que não acabado, que à diferença dos outros animais, deve se completar fora de sua primeira natureza, isto é, em uma segunda natureza, geralmente chamada cultura. Uma cultura no centro da qual reina em alguma medida um grande Sujeito. 0 que poderia se reformular assim: o homem é um neóteno que tenta se cuidar se tornando um animal teológicopolítico, quer diver, um "animal que venera", como dizia Nietzsche.

Isso quer dizer que a sobrevida do homem, animal neotênico, faltoso como tal na natureza, passa pela criação de seres de sobrenatureza, isto é, seres de cultura que, embora não existam, se revelam dotados de uma potente eficácia simbólica.

Assim, é muito cansativo criar seres de sobrenatureza. É preciso de fato mobilizar todas as capacidades de representação sonora, visual e narrativa a fim de dar uma aparência, uma figura, uma voz, uma história, uma residência a este grande Sujeito que a despeito da presença, é preciso representar, inclusive sob a forma do irrepresentável.

Em suma, a arte (narrativas, música, artes plásticas...) serve para criar o grande Sujeito. Melhor: a arte, é a arte de criar o grande Sujeito. Dito de outro modo, o que falta na natureza, se inventará então na cultura, graças à linguagem, graças às narrativas, graças à arte, graças aos mitos. Este é então o trabalho da cultura: ele simplesmente permite a subjetivação. No momento em que este grande Sujeito está localizado, se obtém como efeito a estrutura fundamental da subjetivação na qual se coloca abaixo o pequeno sujeito e, acima, o grande Sujeito. Podemos dizer, então, que a assunção subjetiva passa pela suposição do Outro, grande A.

Este remédio simbólico à aflição real do homem certamente revela o que Platão chamava de pharmakon: um remédio e um veneno (Derrida, 1972) ${ }^{5}$. Em suma, o Outro, este grande Sujeito que não existe, é de uma grande ajuda... até que ele se torna extremamente embaraçante.

A suposição do Outro é um remédio porque me tira de minha aflição originária e é um veneno porque me aliena no Outro. Em outros termos, esta estrutura, como dizia Freud, produz a neurose. A neurose resulta, de fato, da dívida simbólica contraída no lugar do Outro. O que nos conduz a algumas considerações clínicas.

Esta estrutura produz a neurose porque ela me incita a crer que, no mundo no qual eu vim parar, é o Outro que dá, e que eu, o considero tudo. Ele me faz especialmente duas doações, uma real (a vida) e outra simbólica (a linguagem), tão exorbitantes uma e outra que eu não poderia nunca reembolsá-las. De modo que eu não posso outra coisa senão me culpabilizar.

Esta estrutura permite, me parece, dar uma nova forma, ultrapassando a clínica individual, ao que Freud havia chamado, em texto tão breve quanto decisivo, dentre seus últimos, a divisão subjetiva (a Spaltung) (Freud, 1938) ${ }^{6}$. A divisão subjetiva é o que faz com que nós sejamos seres clivados, não nos encontrando nunca verdadeiramente, porque, no momento em que poderíamos 
nos encontrar, nós perdemos no Outro. Esta é uma questão que Lacan trabalhou muito no sentido em que ele explorou sistematicamente os efeitos do recalque originário produzidos pela confrontação do sujeito perante o grande Sujeito, isto é, tal ou tal figura do Outro.

Acredito, no entanto, que devamos retomar hoje a questão. Por quê? Porque Lacan foi um homem de seu tempo, quer dizer, um homem dos tempos estruturalistas que privilegiaram a sincronia e revelaram que existia um Outro de estrutura. Assim, talvez agora seja tempo de passar à diacronia, quer dizer, para a questão da variação histórica das figuras do Outro. É a condição para passar da clínica à política. Quero dizer que o Outro, este ser de ficção que não existe, não pode realmente ser percebido em sua eficácia senão se o abordamos, identificamos e repertoriamos, digamos, seus diferentes avatares. É por isso que me dei como programa me engajar em uma localização histórica das figuras do Outro. O que me conduziu a pensar que a história humana se caracteriza por uma renovação permanente da figura do Outro.

$\mathrm{E}$, de fato, no momento em que nos endereçamos à história, encontramos este Outro em todos os mundos possíveis construídos pelo homem. Seja sob a forma do Totem, por exemplo, pela qual um grupo de homens designam um macho dominante (o Totem, que muito interessou Freud, faz remontar as filiações à uma potência da primeira natureza, um falcão, um jaguar ou um outro "verdadeiro" animal, de modo que o anima do grupo encontra o Animal...). Seja sob a forma dos espíritos que habitam, quer dizer, que assombram, os lugares em que residem os homens. Seja sob a forma de deuses imanentes ao mundo que, como os deuses gregos da Physis por exemplo, intervêm sem cessar nas relações do homem. Seja sob a forma de um Deus transcendente, como nos monoteísmos, que figura um Pai absoluto, eterno. Seja mesmo sob a forma de religiões políticas, como no absolutismo real. Mas este grande Sujeito era provavelmente grande demais, já que foi preciso diminuí-lo, quer dizer, Ihe cortar, quer dizer, Ihe cortar a cabeça. Isso se chama a revolução francesa, que não decapitou o Rei, grande Sujeito do Antigo Regime, senão para fazer aparecer um novo grande Sujeito, o Povo. Não esqueçamos, enfim, as religiões políticas que o século XX conheceu, como o stalinismo, que apresentava o Proletariado como o salvador e como o nazismo que celebrava uma suposta raça superior. Todos estes Outros possibilitaram a função simbólica na medida em que eles deram um ponto de apoio para que estes discursos repousassem sobre um fundamento. Mas, certamente, alguns foram mais perenes que outros.

Assim, vocês sabem que há três décadas, em 1979, exatamente, e é lá onde minha moção filosófica reaparecia, o filósofo J. F. Lyotard fez a hipótese da aparição de uma pausa na 
modernidade. Em um notório ensaio intitulado $A$ condição pós-moderna, que apareceu um ano depois da tomada do poder pelos neoliberais nos dois mais importantes países do mundo, Thatcher, na Inglaterra, e Reagan, nos Estados Unidos, Lyotard notava que nós estávamos saindo da modernidade e entrando em uma época "pós-moderna" - Lyotard entendia por aí o esgotamento das grandes narrativas de fundação. Neste audacioso livro, Lyotard anunciava - sem parecer regozijar demais com isso, nem oprimido, aliás - o novo dado: nós estávamos saindo das grandes narrativas teórico-políticas tanto as antigas (a dos monoteísmos), quanto às modernas (as narrativas de emancipação individual pelo acesso à razão crítica - Kant - ou aqueles da emancipação societária - o marxismo, por exemplo). Assim, a queda das grandes narrativas é também a queda das figuras do Outro que essas narrativas sustentavam. Eis, portanto, na pós-modernidade, nossa estrutura pesadamente atingida. 0 que não pode senão estabelecer uma transformação muito radical da condição subjetiva. Quero dizer que o fato de ser sujeito se apresenta hoje, em nossas democracias de mercado, sob uma modalidade tão sensivelmente diferente daquela que foi para as gerações precedentes. Em suma, não hesitaria em conjecturar que o sujeito que se apresenta hoje não é mais globalmente o mesmo que se apresentava há uma geração. Digo, portanto, que a própria condição subjetiva está também subordinada à variação histórica e que acabamos de atravessar, a esse respeito, um momento importante, que estabelece um profundo remanejamento das grandes instituições, como a família, escola, sem esquecer as instituições de cuidados.

É por isso que, após ter falado de declinar as figuras do Outro (como se declina uma identidade), eu gostaria agora de falar do declínio do Outro - em suma, após declinar, o Outro se inclina. É certamente interessante que os ídolos colapsam, como desejava Nietzsche, mas não seria preciso ignorar os sérios problemas que isso coloca. Pois a pós-modernidade não tem mais as figuras apresentáveis do Outro a propor. Se os períodos precedentes definiam espaços marcados pela distância entre o sujeito e aquele que o funda, então a pós-modernidade é um espaço definido pela abolição da distância entre o sujeito e o Outro.

De fato, do Outro, temos, de agora em diante, o Mercado. O Mercado que é frequentemente apresentado como o remédio contra todos os males. Exceto que o Mercado não funciona mais realmente como uma grande narrativa, mas, acima de tudo, como uma soma infinita de pequenas narrativas egóticas. É por isso que o Mercado não vale a pena como novo Outro, na medida em que, longe de se encarregar da questão da origem, ele confronta cada um aos tormentos (que certamente não vão sem novos gozos) da auto fundação. É aí que se localiza o limite fundamental da economia de mercado em sua pretensão de se encarregar do conjunto do laço pessoal e do laço social: não é uma economia geral, não é uma economia simbólica, mas somente uma "economia econômica". Ela joga no registro da economia libidinal na medida em que ela sempre permite apresentar um objeto 
manufaturado, um serviço comercial ou um fantasma sob medida produzido pela indústria cultural, supostamente vindo preencher todas apetências, mas ela falha em funcionar como o que Bataille chamava como uma economia geral, na medida em que ela deixa o sujeito face a ele mesmo nisso que se refere à sua fundação.

Essa distância interna do sujeito a ele mesmo se descobre inerente ao sujeito pós-moderno e modifica sensivelmente o diagnóstico de Freud sobre o sujeito moderno trazido na neurose. É, acredito, em direção a uma condição subjetiva definida por um estado-limite entre neurose e psicose que se define mais adiante o sujeito pós-moderno, cada vez mais pego entre melancolia latente (a famosa depressão), confusão interior, impossibilidade de falar em primeira pessoa, ilusão de onipotência e fuga para o futuro nos falsos self, nas personalidades de empréstimo, ofertadas em profusão pelo mercado.

Um dos efeitos diretos deste novo dado é que certos sujeitos se sentiram órfãos do Outro e buscaram, como eles podiam evitar a falha do Outro.

Por exemplo, quando o Outro falta, pode-se tentar reinscrever o Outro não mais na ordem do desejo, mas da necessidade. A mercadoria pode desempenhar este papel. Se vê assim desenvolverem-se verdadeiras adiç̧ões à mercadoria. A todas as mercadorias, mas a uma em particular, aquela que se beneficia do terrível privilégio de ser ilícita, rara e cara, portanto, extremamente tentadora dentre todas as mercadorias, vou falar, é claro, da droga. Com a droga, se reinscreve o Outro na ordem não mais do desejo, mas da necessidade. É o que acontece na toxicomania, onde a questão não é mais fazer da dificuldade de existir uma busca simbólica, onde o que vem tamponar a imperfeição usual do Outro deve ser sabiamente construído e exprimido, especialmente pela criação artística (poemas, dança, canto, música, pintura...). Na toxicomania, esta laboriosa busca é transformada em uma simples dependência a respeito de um Outro saído do campo do desejo e reinscrito de certo modo no real da necessidade. Ao menos, se saberá assim onde está e o que do Outro do qual se sente falta: nada mais do que um produto químico tão aditivo quanto possível que se poderá obter na condição de que se torne escravo. Conhecemos os efeitos devastadores do uso intensivo, não falo do uso ocasional, de drogas vizinhas.

Segundo exemplo, quando o Outro falta, pode-se prescindir do Outro na condição de encontrar a si mesmo investido, apenas durante alguns minutos, dos signos da onipotência que o caracterizavam. Nos casos extremos, se poderá mesmo conceder direito de vida e morte sobre seus semelhantes e se dotará eventualmente de poderes mágicos mais facilmente que o prestígio social das tecnociências, reforçando constantemente o ambiente protético, o que não vai sem exaltar os sentimentos de onipotência do sujeito (câmera GoPro, armas sofisticadas, tecnologias numéricas da imagem, do som, da internet, da internet, que permitem a qualquer um se endereçar ao mundo inteiro...). Os atos de violência mais crus podem então se impor sem nenhuma contenção. Não se conta mais, desde os primórdios da pós-modernidade, as passagens ao ato violento que são noticiadas. Desde o crime do cabo Lortie na Assembleia Nacional de Québec, em 1984, até a matança 
na escola primária de Sandy Hook nos Estados Unidos, o número de massacres e de assassinatos aumenta de ano em ano (330 massacres de massa em 2015 nos Estados Unidos, contabilizando segundo alguns perto de 14.000 mortos).

Terceiro exemplo, quando o Outro falta, podemos erigir com toda força um tipo de Outro que assegurasse absolutamente o sujeito contra todo risco de ausência. É isso que se vê em curso em múltiplas seitas que florescem nas sociedades pós-modernas - um pequeno grupo se reúne, brande a efígie de um guru ou de um novo mestre absoluto ou de um deus arcaico vingador e selvagem. Eu não insisto, mas estou bem tentado a dizer que na época da globalização, este confronto pode tomar, com os fundamentalistas, uma evolução global: Jihad contra Marché total.

E eu diria, para terminar, que nada interdita esses órfãos do Outro de combinar estas diferentes tendências. Encontramos cada vez mais sujeitos que são ao mesmo tempo adictos, sujeitos na onipotência e inclinados ao radicalismo fundamentalista.

Todas estas tendências são analisáveis como reações à perda dos pais e das balizas provocada pela cultura pós-moderna. Mas a história, contrariamente ao desejo dos aduladores do Mercado, nunca para. Estas formas justificam o presságio da aparição próxima de um outro regime clínico-político, não mais ultrademocrático, mas ultra autoritário, renovando as antigas religiões políticas fascistas das quais acreditávamos (erradamente) termos nos libertado há décadas. Em outros termos, a globalização neoliberal, que dissolveu as identidades nacionais, os patriarcados e as pátrias, provoca uma reação e a reaparição de ideologias identitárias autoritárias - isso se eleva por todo canto no que se costuma chamar no Brasil o "primeiro mundo, quer dizer, na Europa e nos Estados Unidos, com o "trumpismo". O que poderia ser o presságio de um próximo grande reviramento, pois o ethnos, mais do que o démos, pela primeira vez em 70 anos (o fim da segunda guerra mundial), requalificaria em alguma medida o Outro.

Poderíamos dizer que tudo isso - estas formas sempre renovadas que o Outro não cessa de tomar ao longo da história - resulta do incessante e incerto tratamento narrativo da neotenia humana. $\mathrm{O}$ que se traduz por um simbólico lastreado em seu centro por uma forma de imaginário sobre determinante inclinado a bruscos reviramentos, exibindo, frequentemente, contra algumas cenouras, muitas varas.

Mas, enquanto a humanidade continua a se contar histórias (evidentemente vãs), algumas pessoas se põem a pensar que poderia existir não somente um tratamento simbólico, mas também e sobretudo um tratamento rea/ do problema de que sofre constitutivamente o humano. Saímos da pós-modernidade para entrar (perfeitamente cegos) em uma era nova: a da pós-humanidade. Se tratará agora de tentar localizar, graças às tecnociências, o erro humano, em vista de refazer melhor, ao menos o esperamos, este neóteno vindo das profundezas. Está aí toda a temática hoje sustentada 
pelo pós-humanismo. A do homem aumentado, onde o homem se torna um puro e simples OGM, um organismo geneticamente modificável.

Eu esgotei meu tempo de fala, me permito então remeter ao fim de meu livro, onde examino o que é esta nova forma de loucura humana onde o homem, sustentado por uma paixão faustiana que não é mais somente de encantamento, mas operante, poderia, graças às tecnociências, mudar o real do homem.

Confesso que, da minha parte, meu grande embaraço em escolher entre os tratamentos narrativos atualmente disponíveis (grosso modo, o Mercado, o Jihadismo ou o Trumpismo, três formas do pior) e um tratamento real próximo que propõe de algum modo cuidar do adoecimento fazendo pura e simplesmente desaparecer a doença.

Mas talvez meus amigos psicanalistas saibam sugerir um tratamento aceitável. Eu escuto então a vocês e lhes agradeço.

Tradução: Flavia Lana Garcia de Oliveira Revisão: Tania Coelho dos Santos

\section{Notas:}

${ }^{1}$ Texto apresentado pelo autor no VI Simpósio do ISEPOL, em 30/09/2016.

${ }^{2}$ Dufour, D.-R. (2005). On achève bien les hommes. Paris: Denoël, traduzido sob o título $A$ existência de Deus comprovada por um filósofo ateu, Rio de Janeiro, 2016.

${ }^{3}$ Faço referência às pesquisas que são desenvolvidas (sob o nome de "antropologia filosófica") na sequência dos trabalhos de Louis Bolk ("Le problème de la genèse humaine" - Das Problem der Menschwerdung, de 1926). Elas passam pelos autores da língua alemã como Adolf Portmann e Arnold Gehlen e se prolongam pelas pesquisas decisivas do americano Stephen Jay Gould, cuja teoria da neotenia é desenvolvida em Ontogeny and Phylogeny, pela Harvard University Press, em 1977.

${ }^{4}$ Esta forte proposição concernindo o homem não escapou a Lacan, já que ele a cita em seu seminário $A$ ética (na aula de 13 de Janeiro de 1960). O que tende a mostrar que, se queremos compreender alguma coisa no simbólico, é preciso partir do... diabólico.

${ }^{5}$ Remeto certamente à leitura do Fedro de Platão por Jacques Derrida, "La pharmacie de Platon".

${ }^{6} \mathrm{O}$ termo alemão Spaltung é a tradução por Freud de uma expressão frequente na psiquiatria francês, a de "dissociação" referente, entre outros, ao que Pierre Janet chamava de "dupla consciência". O tomamos em francês também como "clivagem".

${ }^{7} \mathrm{O}$ site americano Gun Violence Archive (GVA), fundado em 2013, após a matança da escola de Sandy Hook, contabilizou em 2015, nos EUA, 52666 incidências envolvendo armas de fogo (10\% a mais que o ano precedente), dos quais 330 massacres de massa, somando-se ao todo 13350 mortos e 26940 feridos. 


\section{Referências Bibliográficas}

Derrida, J. (1972). La pharmacie de Platon. La dissémination. Paris: Seuil.

Dufour, D.-R. (2005). On achève bien les hommes. Paris: Denoël.

Freud, S. (1993). Inhibition, symptôme et angoisse. Paris: PUF (Trabalho original publicado em 1926).

Freud, S. (1938). La scission du moi dans le processus de defense. Recuperado de: http://www.psychanalyse.lu/articles/FreudScission.htm.

Gantheret, F. \& Lapassade, G. (1961, mar.-abr.). Le problème de la genèse humaine. Revue française de Psychanalyse, 243-279.

Gould, S. J. (1977). Ontogeny and Phylogeny. Harvard: University Press.

Lacan, J. (1975). La Troisième. Lettres de I'École Freudienne, 1(16), 177-203. Paris: ECF.

Lacan, J. (1986). Le séminaire, livre 7: l'éthique de la psychanalyse. Paris: Seuil (Trabalho original publicado em 1959-1960).

Citacão/Citation: Dufour, D.-R. (mai. a out. 2016). O Outro lacaniano, uma razão no real. Revista aSEPHallus de Orientação Lacaniana, 11(22), 20-30. Disponível em www.isepol.com/asephallus. doi: 10.17852/1809709x.2019v11n22p20-30.

Editor do artigo: Tania Coelho dos Santos.

Recebido/Received: 01/06/2016 / 06/01/2016.

Aceito/Accepted: 05/06/2016 / 06/05/2016.

Copyright: (c) 2013 Associação Núcleo Sephora de Pesquisa sobre o moderno e o contemporâneo. Este é um artigo de livre acesso, que permite uso irrestrito, distribuição e reprodução em qualquer meio, desde que o autor e a fonte sejam citados/This is an open-access article, which permites unrestricted use, distribution, and reproduction in any medium, provided the author and source are credited. 